\title{
Carrageenan-containing Gel
}

National Cancer Institute

\section{Source}

National Cancer Institute. Carrageenan-containing Gel. NCI Thesaurus. Code C115961.

A water-based, vaginal moisturizing gel containing a mixture of lambda- and kappacarrageenans, sulfated polysaccharides derived from red seaweed (Chondrus crispus), with potential microbicidal activity ag ainst various viruses, including human papillomavirus (HPV), human immunodeficiencyvirus (HIV) and human herpes simplex virus (HSV). Upon vaginal insertion via an applicator, carrageenan specifically binds to the viral capsids, which prevents the binding of virions to heparan sulfate proteoglycan (HSPG) receptors or other, as of yet not fully identified, cellular proteins. In addition, the viral binding of carrageenan may also interfere with conformational changes within the virions after cellular attachment. This inhibits viral infection. Certain HPV types cause cervical cancer; therefore, the prevention of HPV infection by this gel may subsequently prevent the development of cervical cancer. 